\section{Erdnuss-Allergie kann sich „auswachsen“}

\author{
Ernuss-Allergien „wachsen“ sich öfter aus als bislang vermutet. \\ Bei niedrigen Titern an spezifischem IgE lohnt sich daher ein \\ kontrollierter Provokationstest.
}

W ährend $80-85 \%$ der Hühnereiweiß- und Kuhmilch-Allergien nach einigen Jahren verschwinden, galt die Diagnose Erdnuss-Allergie bis vor kurzem als ein „lebenslängliches“ Urteil. Möglicherweise sind aber Kinder mit „ausgewachsener“ Erdnuss-Allergie den Allergologen bisher einfach verlorengegangen.

Deshalb untersuchten Pädiater an der John Hopkins University in Baltimore 223 Kinder und Jugendliche im Alter von über vier Jahren mit anamnestisch bekannter Erdnuss-Allergie mit einem CAP-RAST-Test (Pharmacia).
Bei 126 (56,6\%) dieser Patienten ergaben sich weniger als $20 \mathrm{kU} / \mathrm{l}$ Erdnussspezifischer IgE-Antikörper. Von 85 Patienten, die sich einem Provokationstest unterzogen, zeigten 48 (56,5\% bzw. $21,5 \%$ der Gesamtpopulation) keine Reaktion mehr auf Erdnuss-Allergene. Bei zwei Drittel der Patienten mit IgEWerten unter $2 \mathrm{kU} / \mathrm{l}$ und bei $61 \%$ derer mit weniger als $5 \mathrm{kU} / 1$ hatte sich die $\mathrm{Al}$ lergie „ausgewachsen“.

Ein weiterer guter Prädiktor sind die anfänglichen Reaktionen auf Erdnuss-Allergene: Patienten, die ausschließlich Hautreaktionen gezeigt hat- ten, hatten signifikant bessere Chancen, die Allergie zu verlieren. Allerdings sind diese Parameter nicht absolut zuverlässig: So reagierten acht Patienten mit negativen RAST-Ergebnissen im Provokationstest sehr wohl positiv bis hin zu generalisierten Reaktionen mit Multiorgan-Beteiligung.

\section{Fazit}

Etwa jedes fünfte betroffene Kind hat gute Aussichten, seine Erdnuss-Allergie loszuwerden. Ein jährlicher RAST ist deshalb nach Ansicht der Autoren indiziert. Liegen die IgE-Titer unter $5 \mathrm{kU} / \mathrm{l}$, sollte man dem Patienten einen Provokationstest anbieten - allerdings unter stationären Bedingungen.

jfg

\section{Skolnick HS et al. The natural history of peanut allergy. J Allergy Clin Immunol} 2001; 107: 367-74.

\section{Persistenz von Kuhmilch-Allergie durch bestimmte IgE-Epitope von $\alpha_{\mathrm{s} 1}$-Casein?}

Das Persistieren einer Kuhmilch-Allergie über das zweite oder dritte Lebensjahr hinaus ist möglicherweise mit IgE-Antikörpern gegen bestimmte lineare Epitope von $\alpha_{s 1}$-Casein verbunden.

asein ist eines der Hauptallergene der Kuhmilch, und der größte Anteil davon, $\alpha_{s 1}$-Casein, macht rund ein Drittel des gesamten Milchproteins aus. Allergologen an der „Mount Sinai School of Medicine" in New York City synthetisierten 96 Dekapeptide, die überlappend die gesamte Sequenz des 199 Aminosäuren langen Proteins abdeckten. Anschließend testeten sie die Bindung dieser Peptide mit IgE- und IgG-Antikörpern aus dem Blut von Kindern mit Kuhmilch-Allergie. Sie fanden sechs IgE- und fünf IgG-bindende Peptide, gegen die mehr als 50\% der Patienten teilweise starke Reaktionen zeigten. Bei den IgG-Epitopen gab es keine Altersunterschiede. Zwei der IgE-Epitope (Aminosäuren 69-78 und 173-194) wurden dagegen nur von Kindern im Alter von über neun Jahren erkannt, aber von keinem einzigen un-

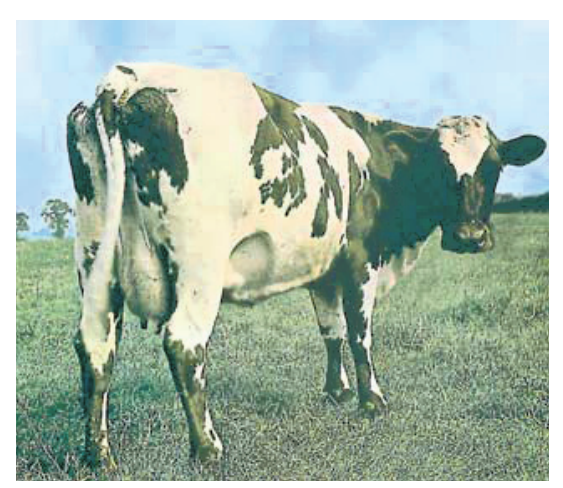

Sie gibt ihr Bestes und ahnt dennoch nichts von $\alpha_{s 1}$-Casein-IgE-Epitopen.

ter drei Jahren, wo noch gute Aussicht besteht, die Allergie wieder zu verlieren.

Von drei Patienten mit persistierender Kuhmilch-Allergie standen Paare von Serumproben - aus einem Alter von weniger als drei Jahren sowie zwi- schen sieben und elf Jahre später - zur Verfügung. Frühe und späte Proben unterschieden sich hinsichtlich erkannter IgE-Epitope kaum, insbesondere wurden die Peptide 69-78 und 173-94 sowohl von den ersten als auch von den zweiten Proben erkannt. Die Reaktion war in den später genommenen Proben mindestens so stark, teilweise noch stärker als in den früheren.

\section{Fazit}

Die sich hier andeutende Rolle der beiden IgE-Epitope 69-78 und 173-194 $\operatorname{des} \alpha_{s 1}$-Caseins für die Persistenz einer Kuhmilch-Allergie über das dritte Lebensjahr hinaus muss sicherlich in prospektiven Untersuchungen bestätigt werden. Im positiven Fall könnte sie dazu dienen, die $15-20 \%$ der Patienten, denen eine solche Chronifizierung droht, frühzeitig zu identifizieren. Dies wäre vor allem lohnend, wenn einmal eine wirksame Immuntherapie verfügbar sein sollte.

jfg

Chatchatee $\mathbf{P}$ et al. Identification of IgEand IgG-binding epitopes on $\alpha_{s_{1}}$-casein: Differences in patients with persistent and transient cow's milk allergy. J Allergy Clin Immunol 2001; 107: 379-83. 